\title{
Learning Alphabets Through Infographics
}

\author{
Michael Olubunmi Odewumi' \\ Grace O. OPUTA, Grace $0^{2}$ \\ Isyaka Bello3
}

Educational Technology, University of Ilorin, Nigeria ${ }^{1,2}$

Educational Technology \& Library Studies, Obafemi Awolowo

University, Nigeria ${ }^{3}$

Email: agbegilerebunmi@gmail.com¹

http://ojs.unm.ac.id/index.php/Insani/index

Abstract. Early stages of reading and writing rest solely on the alphabet. Learning of letters with infographics in the elementary classes makes learning more easy and meaningful. The study examined the potentials of infographics in enhancing learning at an early childhood level especially on letters. The researcher utilized experimental design which including pre and post-test. The package was validated by experts with a reliability coefficient of 0 . 77. The findings of this study showed that the experimental group means a score of 30.60 is higher than the control group means a score of $30.50 \mathrm{co}-$ efficient. Moreover, the means score of 30.742 for females and 30.345 for male pupils was obtained. The study concluded that children at the early childhood level could learn better using infographics based approach. It was recommended that incentives should be provided for pre-school teachers to participate in highly effective staff development to help them integrate infographics into their teaching and learning. Also, infographics based approach be used for all subjects in early childhood education in Nigeria.

Keywords: Creativity, Colour, Early childhood, Learning, Infographics.

\section{INDONESIAN JOURNAL OF EDUCATIONAL STUDIES (IJES)}

\section{E-ISSN: 2621-6744 P-ISSN: 2621-6736}

Submitted: March, $4^{\text {th }} 2019$

Accepted: May, $2^{\text {nd }} 2020$

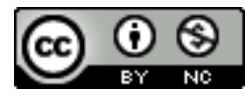

This work is licensed under a Creative Commons Attribution-NonCommercial 4.0 International License 


\section{INTRODUCTION}

This dispensation age has given individual learners of school-age global chances to develop their creativity to the fullest extent by individuals for the benefit of themselves for the future and the communities. Creativity can be described as an act of utilizing, turning, and imaginative ideas into reality through the processes of thinking and producing which are exhibits in different behavioural acts in individuals. In essence, Burke (2007) and Al-Mohammadi (2017) expressed that .creativity is how an instructor captivates learners through inspiring them to knowledge via letters, colours, and visuals. In essence, creativities in letterings, visuals, and colours are associates with infographics.

Infographics can be seen everywhere, it is a combination of graphical, pictorial, and alphabetical words for instructions (Ervi 2016). Infographic combines beautiful text along with the visual to deliver vital information which makes infographic unique in the process of teaching and learning (Damyanov \& Tsankov 2018). Researchers has expresses infographic in different forms. For example, the study of Doug (2004) described info-graphics as information that is a visual representation of knowledge, information, and data to others. Also, Heer, Bostock, and Ogievetskey (2010) expressed info-graphics as all messages that deliverers textual content promptly and effectively. Similarly, Mark (2012) expressed that infographics are a category of representation that blend data, text, and design, purposely to assists organizations and individuals in communicating crucial messages to targeted listeners. In the same vein, Rajamanickam (2007) revealed that infographics represent visual information along with given textbased content for easy decoding and comprehension for a wider audience. Along the same idea, Eissa, (2014) referred to infographics as information and data delivery easier for individual perception and recognition.

According to Mansour (2015) infographics is defined as a storytelling that people use to visualize records in a way of illustration, knowledge, and experiences in a logical manner. Also, Gallicano, Ekachai, and Freberg (2014) submitted that info-graphics are representations of visual information of facts, data, and knowledge which are intends to give information to a selected group of people. In the same vein, Duchowski (2007) maintained that Infographics infuse the culture as a leading form of informational display and communication and it gives a vivid insight into how a scene is perceived. Also, Dick (2013) mentioned that infographics are an innovative aspect that utilises various visual components in reasonably presenting information and content.

In another development, Infographics has been classified as a means of educating people. For example, Shafipoor, Sarayloo, and Shafipoor (2016) stressed that utilising infographics assists learners to keep memory of remarkable information in minds for a long time. Also, the study Ciftci (2016) stressed that infographics are valuable assets in improving the quality of students learning of geography. Likewise, Pisarenko and Bondarev (2016) mentioned the usefulness of infographics for the learning of foreign languages is positive. Never the less, the study of Beymer (2007) confirmed that infographics judiciously use clear symbols, bright colours, legible letterings, and visuals representation in a logical way for understanding and interpreting the cognitive state of mind of an individual through the sense of sight and the given content.

Literature reviewed the benefit of infographics to learning from different perspectives. For example, the study of Baglama, Yucesoy, Uzunboylu and Özcan (2017), submitted that info-graphics as a rich texts and visuals that appeal to the readers, interpret the abstract concepts and organize information into meaningful knowledge to 
facilitate retention and fosters problems solving in individual learners. Also, it an instructional device that cuts across educational disciplines and services for effective communication devices to learners (Mark, 2012). In the same vein, Heer, Bostock, and Ogievetskey (2010) equated infographic with social networking sites that is prominent in given instructional tips, educational information, and spread the facts globally. Similarly, Barboza (2013) agreed that infographic sustains the attention of the audiences on specific information. It also stimulates the interest of learners and increases their full involvement in instructional purposes (Mark, 2012). Infographics is an instructional resource with detailed illustrations and graphical contents, in diverse media (Lankow, Ritchie, \& Crooks, 2012).

Al-Ba'aly (2013) mentioned the positive of infographics for teaching and its importance on the pattern and development of learners. Also, Shaltout and Fatani (2017) expressed that infographics promotes adequate information delivery to the learners. Many scholars have worked on infographics. For example, the study of Sudakov, Bellsky, Usenyuk, and Polyakova (2014) worked on infographics and integration of mathematics, the results revealed the benefit and significant of infographics in relating mathematics. Also, Hafeth (2013) examined the effectiveness of utilising the visual sensitivity on a computer to develop female pupils, the results that computer has a strong influence on developing sense skills. In the same vein, Coleman (2010) expressed how teachers use charts in promoting educational motives at Alabama University.

The significance of infographics has been looked into by many scholars. For example, Smiciklas (2012) expressed that Info-graphics encourages pupils creativity in learners through tools and materials. Info-graphics enhances a positive impact on learning and visual communication (Vanichvasin, 2013). Broadens pupils learning and comprehension in education (Farrell, 2013). Combined content and knowledge to create visuals for learners' instruction (Doug, 2004). Utilises, images, diagrams, and animations purposely to communicate messages and instructions (Mark, 2012). Increasingly great through the Internet and social media combined with text with visuals, data, knowledge, and information (Bradshaw, 2011). Representing values in visual forms and combining concepts from computer science, data mining, cognitive science and graphic art design to solve instructional and educational problems (Thomas \& Cook, 2004).

On Gender and infographics, the study of Thomas and Cook (2004) expressed that the visual representations, interaction, and communication techniques of info-graphic take advantage in the gender sight are because both the male and female see, explores, and understands of information at glance. Also, Duchowski (2007) submitted that infographics operates on the level of a given sensitivity of colour spectrum, thus varies in perception of both male and female. The author further stressed that female is of sensitivity to colour green, while male prefers other colours like blue or red.

According to Social Learning theory, gender development and gender-typed preference from socialization agents. This is revealed by social behaviours of gender especially, girls' that are more pink and blue colors while boys preferred black colour than other colours. It is also established that parent-child relations are shown in the context of gender understanding and using colour (Campbell, Shirley, \& Caygill 2002; Bandura, 1977; Cohen, 2013).

Teachers in lower classes in educational establishment recognizes the importance of writing with different colour pencils, thereby provides adequate colourful writing materials for the learners (Gerde \& Bingham, 2012). This act tremendously develops and 
articulates the spoken of words and exhibiting of cognitive legible talent of writing effectively (Santangelo \& Olinghouse, 2009). Although literacy skills start from birth through interactions with pictorial and colourful books (Daimant-Cohen, 2007). In essence Chohan (2011) submitted that individual pupil without proper writing skill end up as nuisance to himself and the community at large, he further expressed that pupils taught skillful writing are well articulate, without much problem in education and employment sector. Infographics combined content and knowledge to create visuals for learners' instruction and provide opportunities for exploration, experimentation, and manipulation that are essential for constructing knowledge. Children at the early childhood level learn better by engaging in activities of interest and enjoyment provided in form visuals. Most Nigerian pre-schools are not aware of the effective ways of maximising children's learning by utilising visuals. Drills and memorisation is the commonest feature of the pre-school classes globally.

Studies have revealed that children's performance in reading is generally poor. This has been traced, among other things, the problem of letterings identification in earlystage, poor techniques of teaching, and lack of appropriate teaching resources to commensurate the learning process. In another development, Bazara'a, (2014) established that poor performances on handwriting during the school-age years lead to negative effects on learners academic success and future self-esteem. The study of Osanyin (2004) suggested that nursery school education in Nigeria needs to be equipped with learning resources to be able to give all-round development which will make him/her become an enquirer, an explorer, an investigator and possibly a technologist. The effectiveness of infographics on the pupils learning in early education remains unknown. It is on this that the present study examined the pupils learning and acquisition of knowledge on letterings through infographics in the context of pre-primary education in Nigeria. The main purpose of the study is to investigate the impact of Info-graphic on early childhood learning acquisition especially on 26 letters. The study further investigates the perception of colours, letterings, and visuals on early childhood development in learning.

\section{RESEARCH METHOD}

The research design used for this study was a quasi-experimental design of the pre-test and post-test which consisted of both the conventional and the treatment of the two groups. This class existed as intact groups the pre-test and post-tests were administered on them to determine the quality of instruction before and after the treatment. The population for this study was made up of the entire nursery two pupils in Nigeria. The sample subjects were drawn from two co-educational of Government and Private owned Nursery and Primary Schools. The sample from co-educational nursery and primary schools were selected by the use of stratified random sampling technique. This method was adopted so that the gender variable would be taking care of. The total number of pupils used for the study were sixty (60) that is twenty-nine (29) boys and thirty (31) girls between the age of 9 and 11. The criteria for selection are: the pupils that can read directly from the big screen; pupils that can handle pencil and crayon for legible writings on blank sheet and cardboard and pupils that can answer simple questions while reading from the screen.

The instruments used for the study were an Infographics Checklist (IC), infographics questions (IQ), and the Infographics Designed Package (IDP). The 
infographics designed package was written by the researcher with the assistance of a lecturer in Early Childhood Education (ECE), a computer graphic, a computer programmer, and an educational technology expert. Besides related lettering textbooks and the internet were used for the study. The infographic package on lettering was written based on the curriculum of nursery two pupils on literacy which was later compressed and written in a Compact disk to be played with a laptop and projected on the screen. The infographics designed package was projected for the pupils, thirty minutes per week, for a complete six weeks, before exposing the pupils to evaluation.

The validity of the study instrument was done by the lecturers at the University of Ilorin, Nigeria. Therefore, a lecturer each in the department of educational technology, department of childhood education, department of test, measurement and evaluation, and department of the computer studies. The reliability of the research instrument was administered on the nursery two pupils of another school, using a big screen. The reliability coefficient was computed with the split-half statistical approach and the Richard Kuderson formula 21CKR-2. The output value obtained for this was reliability coefficient 0.77 which was considered to be good enough for the study. The study instrument was further subjected to a pilot study, and the reliability test of (0.77) was obtained.

The study was of six intensive weeks, the first week is used to familiarise the pupils and instructor with the materials and instructions on the study. The pupils were exposed to IDP for four weeks of one hour per week of a normal classroom setting with a big plasma television before the pupils with the instructor given instructions on the watched content. The sixth week is used to evaluate the content and administration of summative questions with a checklist. The conventional group was taught by the pupil's teacher with learning resources both groups were put together and calling on the pupils one by one to administer the question. The scores of the pupils through the checklist were put together for the collection of data used for study statistics.

\section{RESULT AND FINDING}

Table 1. Mean and Standard Deviation on the difference between control and experimental taught using infographics

\begin{tabular}{llll}
\hline Variable & $\mathrm{N}$ & Mean & Std. Deviation \\
\hline Control & 30 & 30.50 & 5.23088 \\
Experimental & 30 & 30.60 & 6.16777 \\
\hline
\end{tabular}

Learning with infographics has a positive influence on student performance. The mean score 30.60 of the experimental pupils which is slightly bigger than that of the conventional group with the mean 30.50 .

Table 2. Mean and Standard Deviation on the difference between male and female taught using infographics

\begin{tabular}{cccc}
\hline Variable & N & Mean & Std. Deviation \\
\hline Male & 29 & 30.344 & 5.25273 \\
Female & 31 & 30.7419 & 6.11538 \\
\hline
\end{tabular}


As shown in Table 2, the female learning with infographics performance is higher than the male performances. The mean score of females 30.742 is slightly bigger than that of male pupils with the means of 30.345 . it shows that males and females had a slight range of between 30.34 to 30.75 respectively.

\section{Testing of the Hypotheses}

ANCOVA statistic was used to compare the means scores of the pupils with the male scores serving as covariates, the result is as reflected in Table 3.

Table 3. Analysis of Covariance (ANCOVA) on the Scores of pupils

\begin{tabular}{lrrrrr}
\hline Source & Type III Sum of Squares & Df & Mean Square & \multicolumn{1}{c}{ F } & \multicolumn{1}{c}{ Sig. } \\
\hline Corrected & $20.765^{\mathrm{a}}$ & 12 & 1.730 & .967 & .513 \\
Model & & & & & \\
Intercept & 16.405 & 1 & 16.405 & 9.163 & .008 \\
Experimental & .871 & 1 & .871 & .486 & .495 \\
Conventional & 11.006 & 11 & 1.001 & .559 & .836 \\
Error & 30.435 & 17 & 1.790 & & \\
Total & 1694.000 & 30 & & & \\
Corrected Total & 51.200 & 29 & & & \\
\hline
\end{tabular}

Table 3 indicates that the calculated $\mathrm{F}$ value of .559 is not significant because the significant value of .836 is greater than 0.5 alpha levels. The result implies that there is no significant difference between the post-test mean scores of the pupils. Therefore, the null hypothesis is hereby accepted. The post-test mean scores of boys and girls pupils were computed using analysis of covariance as pre-test as covariance table 4 .

Table 4. The post-test mean scores of boys and girls pupils using info graphics

\begin{tabular}{lrrrrr}
\hline Source & Type III Sum of Squares & Df & Mean Square & \multicolumn{1}{c}{ F } & Sig. \\
\hline Corrected & $12.168^{\mathrm{a}}$ & 13 & .936 & .866 & .598 \\
Model & & & & & \\
Intercept & 24.173 & 1 & 24.173 & 22.359 & .000 \\
Male & .916 & 1 & .916 & .847 & .371 \\
Female & 12.085 & 12 & 1.007 & .931 & .541 \\
Error & 17.298 & 16 & 1.081 & & \\
Total & 2214.000 & 30 & & & \\
Corrected Total & 29.467 & 29 & & & \\
\hline
\end{tabular}

Table 4 indicates that the calculated $F$ value of .931 is not significant because the significant value of .541 is greater than 0.5 alpha levels. The result implies that there is no significant difference between post-test mean scores of the pupils. Therefore, the null hypothesis is hereby accepted

The result of the findings as shown in table one depicts that learning with infographics has a positive influence on learners' performance. The findings were similar to the findings of Williams (2002) that specified infographics as influencing learners positive thinking styles and influence their arguments. It was also in line with Vanichvasin (2013) who revealed that infographics assist the teacher in presenting their instruction in 
a logical order that catches the pupil's attention and influence the pupil's performances positively.

Furthermore, the finding agrees with Schrock (2014), that infographics increase pupils achievement. Similarly, the findings conform with Matrix and Hodson (2014) who point out that infographics are a device that improves pupils attitudes that leads to effective communication in learning. Moreso, the result of the performance based on gender is in agreement with Yildrim (2016) who stressed that female participants usually prefer visual materials to learning than their male counterparts. In essence, the finding is in line with the findings of İslamoğlu, Ay, İliç, Mercimek, Dönmez, Kuzu, and Odabaşı (2015) who study presented infographic as a provider of new opportunities for both male and female pupils.

\section{CONCLUSION}

In essence, the study concluded that children at early childhood education levels enjoy learning and perform better when a technological based approach is used in the teaching and learning process. Thus, to improve learning, those in the field of early childhood education need to invent new ways of learning that would measure up with the technological advancement of this age. Teachers need to encourage pupils' creativity and enhances positive impact on learning by combining content and knowledge to create visuals for learners and provide opportunities for exploration, experimentation, and manipulation in order to integrate infographics learning approach into the classroom. In respect of the positive aspect of the study, these implications were drawn, Infographics is a useful and powerful tool in teaching and learning at the early childhood level. Teachers can design infographics packages that could assist in the teaching and learning of various subjects at the early childhood level.

Based on the conclusions on the effectiveness of infographics in early childhood education, the following recommendations were made: School authority should provide incentives for pre-school teachers to participate in highly effective staff development to help them integrate technology into their teaching and learning. Parents should purchase mini computers for their children so that they will be able to develop basic ICT skills that would help in improving their performances. Infographics based approach should be used for all subjects in early childhood education in Nigeria.

\section{REFERENCES}

Al-Ba'aly. (2013). Effectiveness of a Proposed Unit at Science According to the Perspective of Costa and Calik for Mind Habits on Developing Analytical Thinking and Scientific Tendencies for the First-Grade Preparatory School Students in the Kingdom of Saudi Arabia. Practical Education Magazine, 5(116).

Al-Mohammadi, A. (2017). Effectiveness of Using Infographics as an Approach for Teaching Programming Fundamentals on Developing Analytical Thinking Skills for High School Students in the City of Makkahin Saudi Arabia. Global Journal of Educational Studies. 3(1)23-42.

Baglama, B., Yucesoy, Y., Uzunboylu, H., \& Özcan, D. (2017). Can infographics facilitate the learning of individuals with mathematical learning difficulties? (ijcrsee) international journal of cognitive research in science, Engineering and Education, 5(2),119-128.

Bandura, A. (1977). Social learning theory. London: Prentice Hall. 
Barboza, C. A. (2013). From Digits to Diagrams: Using Infographics to Inform Database Retention and Cancellation Decisions.

Bazara'a, M. (2014). Can We Use Infographics in Education? Retrieved from https://goo.gl/iQZjgc on the 25th July 2017.

Beymer, D. (2007). An eye tracking study of how pictures influence Online

Bimler, D. L., Kirkland, J., \& Jameson, K. A. (2004).Quantifying variations in personal colorspaces: Arethere sex differences in colour vision? Colour Research and Application, 29, 128-134.

Bradshaw, L. (2011, May 18). CBS Coorporation. Retrieved July 23, 2011, from CBS News: http://www.cbsnews.com/8301-504943_162-20064104-10391715.html

Burke, C. (2007). 'The View of the Child: Releasing 'visual voices' in the design of learning environments', Discourse, 28(3), 359-372.

Campbell, A., Shirley, L. \& Caygill, L. (2002). Sex-typed three domains: Do two-year-olds need cognitive variables? British Journal of Psychology, 93, 203- 217.

Chohan, S. (2011). Any letter for me? Relationships between an elementary school letter writing program and student attitudes, literacy achievement, and friendship culture. Early Childhood Education 39(1), 39-50

Cifci, T. (2016). Effects of infographics on students achievement and attitude towards geography lessons. Journal of Education and Learning, 5(1), 154-166.

Cohen, P. N. (2013). Children's gender and parents' colour preferences. Archives of sexual behaviour, 42, 393-397.

Coleman, J. (2010). Elementary Teachers, Instructional Practices Involving Graphical Representations. Journal of Visual Literacy, 29(2), 198-222.

Daimant-Cohen, B. (2007). First day of class: The public library's role in school readiness. Children and Libraries. 5(1),40-48.

Damyanov, I. \& Tsankov, N. (2018). The Role of Infographics for the Development of Skills for Cognitive Modeling in Education. International Journal of Emerging Technologies in Learning (iJET), 13(1), 82-92.

Dick, M. (2013). Interactive infographics and news values. DigitalJournalism, 2(4), 1-17.

Doug N. \& Jim H., (2004). Public relations writing: form and style p. 236.

Duchowski, A. (2007). Eye tracking methodology: theory and practice. Springer.

Eissa, M. (2014). What is the Infographic? Definition, Tips and Free Tools. Retrieved from http://xnlzecaacca1ag on 12th April 2017.

Ervine. M. D. (2016). Visual literacy in instructional design programs. Journal of Visual Literacy, 35(2),104-113.

Farrell, S. (Producer) (2013). Visual literacy through infographics. International Society for Technology in Education(ISTE) Annual Conference. http://www.youtube.com

Gallicano, T.D., Ekachai, D. and Freberg, K. (2014). The Infographics Assignment: A Qualitative Study of Students' and Professionals' Perspectives. Public Relations Journal, 8(4). Available online:

Gerde, H.K., Bingham, G.E. \& Wasik, B.A. ( 2012). Early Childhood Education Journal40, (6),351-359

Hafeth, A. M. (2013). Effectiveness of Using Visual Approach in Teaching Mathematics Using Computers on Developing Spatial Sensation for Preparatory School Students. Journal of Mathematics Education, 16. 
Heer, J., Bostock, M, \& Ogievetskey, V.(2010). A tour through the visualization zoo. Communications of the ACM, 53(6),59-67.

Islamoğlu, H., Ay, O., İliç, U., Mercimek, B., Dönmez, P., Kuzu, A., \& Odabaşı, F. (2015). Infographics: A new competency area for teacher candidates. Cypriot Journal of Educational Sciences, 10(1),32-39.

Lankow, J., Ritchie, J., \& Crooks, R. (2012)The Power of Infographics: Visual Storytelling. USA: John Wiley \& Sons, Inc

López-Sáez, M., Morales, J.F. \& Lisbona, A. (2008). Evolution of gender stereotypes in Spain: traits and roles. The Spanish Journal of Psychology, 11, 609-617.

Mansour M. (2015). Impact of using infographics based on Marzano's dimensions of learning model on developing e-cloud concepts and productive habits of mind among students at faculty of education. Journal of Faculty of Education, Assiut University. 31(5),126-167

Mark S. (2012). The power of infographics using pictures to communicate and connect with your audience. Wikipedia, free dictionary.

Matrix, S., \& Hodson, J. (2014). Teaching with infographics: Practicing new digital competencies and visual literacies. Journal of Pedagogic Development, 4(2), 17-27.

Osanyin, F. A. (2004). Facilitating effective child care delivery: Parenting environment. Journal of Early Childhood Association of Nigeria, 2(2),42-54.

Pisarenko, V., \& Bondarev, M. (2016). Infographics use in teaching foreign languages for specific purposes. Recent Patents on Computer Science, 9(2), 124-132.

Rajamanickam, V. (2007). Infographics: Being and Doing (Part I). Retrieved August 21st, 2011, from: http://www.uigarden.net/english/infographics-being-anddoing-

Santangelo, T. \& Olinghouse, N.G. (2009). Effective writing instruction for students who have writing difficulties. Focus on Exceptional Children, 42(4),1-9.

Schrock, K. (2014). Infographics as a creative assessment. Retrieved September 29, 2014, from http://www.schrockguide.net/infographics-as-an-assessment.html

Shafipoor, M., Sarayloo, R., \& Shafipoor, A. Infographic (information graphic); a tool for increasing the efficiency of teaching and learning processes. International Academic Journal of Innovative Research, 3(4),39-45

Shaltout, M. and Fatani, H. (2017). Impact of two different infographics types "interactive static" on developing mathematical concepts among female students at second, Internationals Journal of Research and Reviews in Education. IJRRE 4 (2017), 1-8

Smiciklas, M. (2012). The Power of Infographics: Using Pictures to Communicate and Connect With Your Audiences. Que Publishing.

Sudakov, I., Bellsky, T., Usenyuk, S., \& Polyakova, V. (2014). Mathematics and Climate Infographics: A Mechanism for Interdisciplinary Collaboration in the Classroom. Physics Education, 1-8. http://10.1080/10511970.2015.1072607

Thomas, J. J., \& Cook, K. A. (2004). Illuminating the Path: The R\&D Agenda for Visual Analytics. National Visualization and Analytics Center.

Vanichvasin, P. (2013). Enhancing the Quality of Learning Through the Use of Infographics as Visual Communication Tool and Learning Tool. In IQCA '13 (pp. 135-142).

Williams, M. F. (2002). Diversity, thinking styles, and infographics (Paper presented at 12th International Conference of Women in Engineering, Science and Technology, Ottawa 
July 27-31 2002). Retrieved September 30, 2014, from http://www.mun.ca/cwse/icwes infographics.pdf.

Yildrim, S. (2016). Infographics for Educational Purposes: Their Structure, Properties and Reader Approaches. TOJET:The Turkish Online Journal of Educational Technology, 5(3),98-110. 